\title{
Experimental Study of Air Ejector Performance to Cool Agricultural Products
}

\section{Hassan S. Jawad *, Qusay J. Abdul Ghafoor}

Mechanical Engineering Department- University of Technology, Baghdad, Iraq

*Corresponding author Email: s.ritha1001@ coeng.uobaghdad.edu.iq

\section{H I G H L I G H T S}

- The ejector is a device used in the practical applications because it is simple, easy to use, low in cost, simple design and does not contain moving parts.

- It is used to pump high-temperature gases, in air conditioning systems and drying.

- The current method is used to cool agricultural products after harvesting and before storage.

\section{A R T I C L E I N F O}

Handling editor: Muhsin J. Jweeg

\section{Keywords:}

Cooling product

Design parameters

Ejector

Experimental work

Geometry Parameters

Performance analysis

\section{A B S T R A C T}

\section{Introduction}

The ejector uses in practical applications because it is simple, easy to use, low in cost, simple design and does not contain moving parts $[1,2,3]$ The ejector consists of the following parts as shown in Figure 1.

1. Primary nozzle

2. Secondary nozzle

The secondary nozzle that it consists of:-

- Section chamber

- Mixing section

- Diffuser

The ejector operating principle can be summarized as follows:

A fluid with high pressure and high temperature enters the primary nozzle and is called the primary fluid. This fluid expands through the primary nozzle so that it leaves at a high speed and low pressure, which leads to the withdrawal of another fluid from an opening in the intake chamber and is called the secondary fluid. Then the two fluids are mixed in the mixing section and in the final part from the ejector the mixture pressure is raised. 


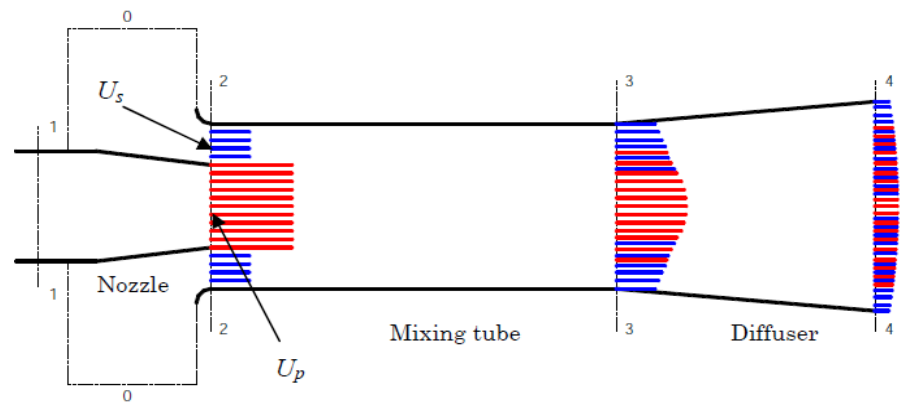

Figure 1: Schematic diagram of an ejector

Watanawanyoo, P., and Chaitep, S. (2014) used the vacuum principle in drying food, and researchers Drouzas, A. E., and H. Schubert (1996) used the vacuum principle by drying banana slices, and other researchers Mucio Furtado\& Alan Wolfschoon (1988) used the vacuum principle in milk pasteurization.

In the current article, we discussed conducting a practical study using the principle of vacuum in the process of cooling food by using air ejector, on the grounds that as a result of evaporation of the product, heat is lost, which is an industrial method currently approved.

Vacuum cooling was actively developed during World War II [4]. The serum sent to Europe from the United States for medical treatment of a wounded person needed to be frozen, but due to the lack of immediate refrigeration and transportation, many of the blood serum supplies were spoiled before reaching the target recipient These applications include food processing and pharmaceutical[2] Temperature is considered one of the most important environmental factors for crop deterioration, and optimal temperature control is considered the most important tool to prevent crop deterioration and maintain its quality. Therefore, cooling in this way is called initial cooling that allows heat to be removed from the product after it is collected before the shipping and marketing process. The vacuum cooling method is based on the evaporation of water from the product at a low temperature, evaporation of water leads to cooling, because the energy needed to convert water from liquid to gas is taken from the product, which leads to its cooling.

\section{Performance of an Ejector}

The performance of an ejector can be measured by a number of dependent parameters e.g. pumping ratio, pressure rise and Mixing etc. The independent variables, which affect the ejector performance, can be divided into two classes, flow and geometry parameters.

\subsection{Flow Parameters}

\subsubsection{Reynolds number}

Reynolds number $(\mathrm{Re})$ is the ratio of inertia force of a fluid stream to the viscous forces.

Mathematically Re is defined as: [1]

$$
\operatorname{Re}=\frac{\rho U D}{\mu}
$$

Where $U$ is the velocity, $\rho$ is the density, $\mu$ is the dynamic viscosity and D is a characteristic length showing the size of the object in the flow. Re is very important parameter for entrainment and mixing of the jets. [1]

\subsubsection{Mach number}

Mach number is the ratio of flow velocity to the speed of sound in the same fluid.

$$
\mathrm{Ma}=\frac{U}{c}=\frac{U}{\sqrt{k R T}}
$$

Where $\mathrm{c}$ is the speed of sound in the same medium, $\mathrm{k}$ is the ratio of specific heats, $\mathrm{R}$ is the gas constant and $\mathrm{T}$ is the temperature in absolute scale. [5]

\subsection{Geometry Parameters}

\subsubsection{Area Ratio}

Figure 2 shows the geometry parameters of an ejector. The size of the mixing tube with respect to the nozzle is given by area ratio Am/An. The area ratio controls the pumping of the ejector.

\subsubsection{Ejector Length}

The length $(\mathrm{Lm})$ of the ejector plays an important role in the mixing and pressure rise of the ejector.

\subsubsection{Standoff (s)}

Standoff (s) is the axial distance between the exit of the nozzle and the inlet section of the mixing tube. A number of studies are showing a marked effect of standoff on the ejector performance. [1] 


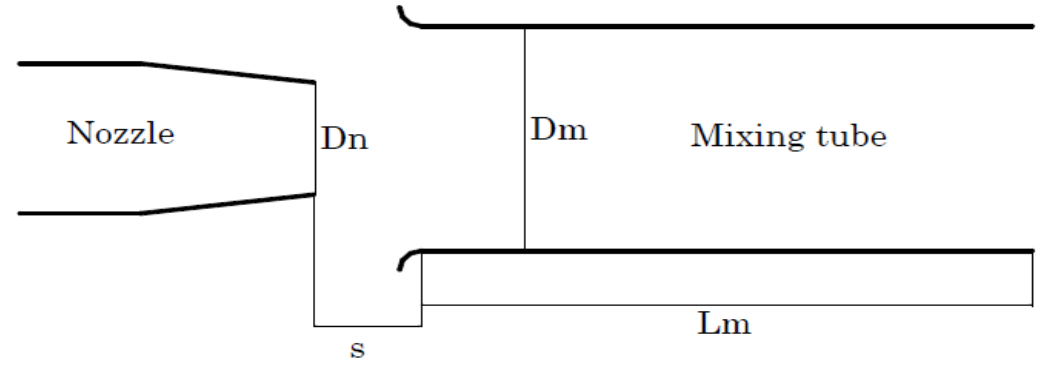

Figure 2: Ejector geometry parameters

\section{Ejector Performance Analysis} follows:

Figure 3 shows a sketch of ejector based on [3,4]. The applicable equations are provided by Huang et al [5, 6] as

- Primary flow (active gas) through nozzle: The HP (active) gas is accelerated to sonic velocity in the throat of the ejector inlet nozzle [7]

$$
\dot{\mathrm{m}}_{\mathrm{P}}=\frac{P_{g} A_{t}}{\sqrt{T_{g}}} \times \sqrt{\frac{\gamma}{R}}\left(\frac{2}{\gamma+1}\right)^{\frac{\gamma+1}{\gamma-1}} \sqrt{\eta_{P}}
$$

- Pressure and Mach number at nozzle exit plane (depends on area at exit of throat)

$$
\begin{aligned}
\left(\frac{A_{P 1}}{A_{t}}\right)^{2} & =\frac{1}{M_{P 1}^{2}}\left[\frac{2}{\gamma+1}\left(1+\frac{(\gamma-1)}{2} M_{P 1}^{2}\right)\right]^{\frac{\gamma+1}{\gamma-1}} \\
\frac{\mathrm{P}_{\mathrm{g}}}{\mathrm{P}_{\mathrm{P} 1}} & =\left(1+\frac{\gamma-1}{2} \mathrm{M}_{\mathrm{P} 1}^{2}\right)^{\left(\frac{\gamma}{\gamma-1}\right)}
\end{aligned}
$$

Eq. (5), however, does not account the isentropic efficiency. Therefore the following adjustment is made:

$$
\eta=\frac{\left(\frac{P_{2}}{P_{1}}\right)^{\left(\frac{\gamma-1}{\gamma}\right)}}{\left(\frac{P_{2}}{P_{1}}\right)^{\left(\frac{n-1}{n}\right)}}
$$

Secondary flow (passive gas) through nozzle:

$$
\frac{P_{e}}{P_{s y}}=\left(1+\frac{(\gamma-1)}{2} M_{s y}^{2}\right)^{\left(\frac{\gamma}{\gamma-1}\right)}
$$

The pressure cross section $y-y$ is required to be lower than that of the passive gas, to ensure sufficient passive gas flow. As the design entrainment ratio increases, the design area for passive gas flow will be increased. Nevertheless, passive gas velocity will be required to increase, thus the pressure at $y-y$ will be required to decrease. The following equations describe the mixing process downstream of the nozzle: [8]

- Momentum balance

$$
\Phi_{\mathrm{m}}\left[\dot{\mathrm{m}}_{P} V_{P y}+\dot{\mathrm{m}}_{s} V_{s y}\right]=\left(\dot{\mathrm{m}}_{P}+\dot{\mathrm{m}}_{s}\right) V_{m}
$$

- Energy balance

$$
\dot{\mathrm{m}}_{P}\left(C_{P, P y} T_{P y}+\frac{V_{P y}^{2}}{2}\right)+\dot{\mathrm{m}}_{s}\left(C_{P, s y} T_{s y}+\frac{V_{s y}^{2}}{2}\right)=\left(\dot{\mathrm{m}}_{p}+\dot{\mathrm{m}}_{s}\right)\left(C_{P, m} T_{m}+\frac{V_{m}^{2}}{2}\right)
$$

Prior to entering the diffuser, the mixed gas velocity reduces less than sonic velocity, consequently a shock wave is generated. The pressure ratio and Mach number of the gas downstream of the shock wave are calculated as follows:

$$
\begin{gathered}
\frac{P_{s}}{P_{m}}=1+\frac{2 \gamma}{\gamma+1}\left(M_{m}^{2}-1\right) \\
M_{3}^{2}=\frac{1+\frac{(\gamma-1)}{2} M_{m}^{2}}{\gamma M_{m}^{2}-\frac{\gamma-1}{2}}
\end{gathered}
$$




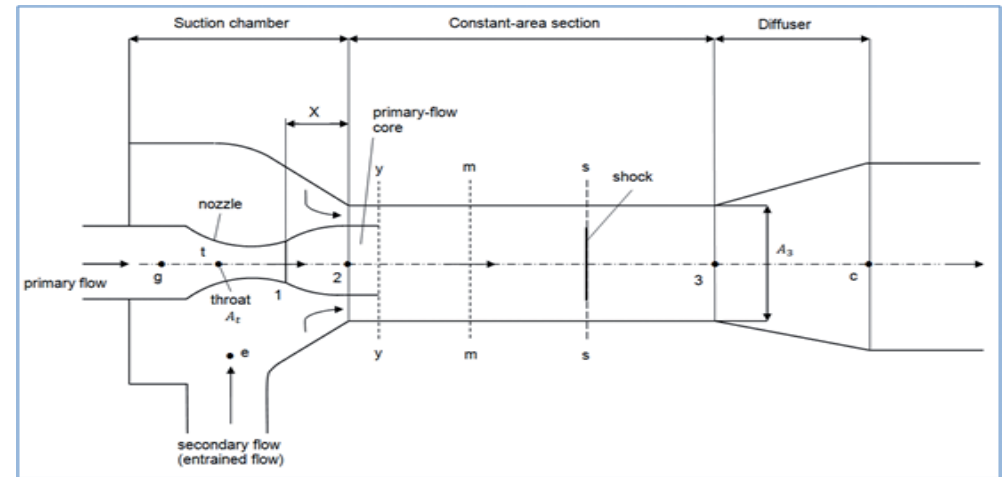

Figure 3: Parts of the ejector according to the above equations [9].

The pressure increase across subsonic diffuser can then be calculated by:

\section{Vacuum Cooling}

$$
\begin{gathered}
\frac{P_{c}}{P_{3}} \sim\left(1+\frac{(\gamma-1)}{2} M_{3}^{2}\right)^{\left(\frac{\gamma}{\gamma-1}\right)} \\
\phi_{m}=a_{1}-\left(a_{2} \times \frac{A_{3}}{A_{t}}\right)
\end{gathered}
$$

The optimum temperature control is one of the most important factors to preserve the product and increase its service life, as after the fruits are collected from the field, a new stage begins, the initial cooling stage, which in turn leads to removal heat from the fruits so that no wilting occurs. It is known physically that the boiling point of water decreases in the case of a decrease in atmospheric pressure. Therefore, when evacuations of air occur around the fruits during a specific period of time, a decrease in atmospheric pressure occurs around the fruit, and this in turn leads to a decrease in the temperature necessary for the evaporation of water from the fruits, and part of the water of the fruits evaporates, carrying with it the excess heat. Therefore, the temperature of the fruit is reduced.

\section{Design Parameters}

\subsection{The length of the diverge part of the primary nozzle}

The length of the diverge part must be determined in such a way as to ensure that the amount of primary fluid moves through it with the least possible losses in the flow. This length can be found after determining the diffraction angle. It was found that the best performance of the primary trumpet when $\Theta$ is equal to $7[10]$.

\subsection{The length of the constant area mixing section}

The length of the constant area mixing section, it is preferred that the length of the constant area mixing section be 3-5 times the diameter of nozzle.

\subsection{Diffuser length}

The length of the diffuser is determined by determining the angle of diffraction. When the angle of diffuser less the diffuser becomes long, which leads to an increase in losses caused by friction and that the ideal value of the angle is from 6-8 degrees [10]

\section{The Ejector Manufactures}

According to the design specifications mentioned in the previous paragraph, the ejector was manufactured from brass metal and from a number of connectable parts. The Table I shows the dimensions of the designed ejector and Figure 4 shows the ejector parts.

Table 1: Dimension of the ejectors. [10]

\begin{tabular}{lccr}
\hline \multicolumn{1}{c}{ Primary nozzle } & \multicolumn{2}{c}{ Ejector main body } \\
\hline Throat diameter $(\mathrm{mm})$ & 1.8 & Inlet section diameter $(\mathrm{mm})$ & 12.5 \\
Exit diameter $(\mathrm{mm})$ & 3.3 & Length of convergent $(\mathrm{mm})$ & 86 \\
Convergent angle & $19.5^{\circ}$ & Convergent angle & $14^{\circ}$ \\
Divergent angle & $7^{\circ}$ & Primary nozzle position, NXP $(\mathrm{mm})$ & 4 \\
Length of convergent $(\mathrm{mm})$ & 13 & Mixing section diameter $(\mathrm{mm})$ & 7 \\
Length of divergent $(\mathrm{mm})$ & 7 & Length of mixing section $(\mathrm{mm})$ & 68 \\
Nozzle external diameter & 6.25 & Length of divergent $(\mathrm{mm})$ & 90 \\
$(\mathrm{~mm})$ & & Divergent angle & $6^{\circ}$ \\
\hline
\end{tabular}




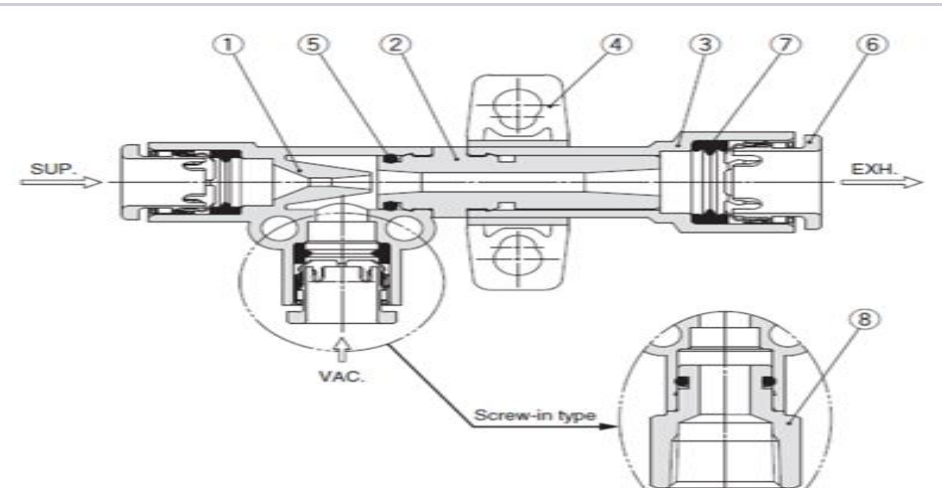

\begin{tabular}{cl}
\hline \hline No. & Description \\
\hline 1 & Body \\
\hline 2 & Diffuser \\
\hline 3 & Adapter \\
\hline 4 & Standard bracket \\
\hline 5 & O - ring \\
\hline 6 & Cassette \\
\hline 7 & Seal \\
\hline 8 & Screw- in stud \\
\hline
\end{tabular}

Component parts

Figure 4: Parts of the ejector

\section{Experimental Work}

We examined the air compressor operation steady by using three different pressure of the nozzles $(2,1.8$, and 1$)$ bar and it was noticed that the compressor with capacity of 25 liters was steady state at a pressure of 1.8 bar, and on this basis, this diameter was relied upon by the design of the ejector. The system was tested using two primary air pressures $(1.8,1)$ bar. For the purpose of determining the performance of the ejector in the process of cooling food, it was connected to an inspection system, as shown in the Figure 5 which shows the locations of control valves, pressure gauges, temperature gauges, speed gauges, and tubes used for push, intake and drain lines. For the driving fluid (air), a mechanical compressor with a maximum pressure of 8 bar was used, a pressure regulator set to control the inlet pressure before entering the primary nozzle. Due to the high thrust pressure after the control valve, a suitable device for measuring pressure is a Borden gauge and a control valve was placed at the suction line and then a pressure gauge for the discharge at the second fluid inlet to the ejector. And put the velocity meter after the control valve. The device used is the hot wire gauge. A vessel filled with water (product) was placed inside the main chamber. Thermometer immersed in tank to measure the required temperature of product. During operation of air compressor with $(1.8,1)$ bar, water vapor generated in the cylinder. This leads to a decrease in the temperature of the product, which is controlled by controlling the vacuum pressure. A stopwatch was used to read the time required for water to reach required temperature.

We note from the Tables II and III:

1) - At an initial pressure of 1.8 bar that the weight loss was $4.8 \mathrm{~g}$, the moisture loss rate was $0.5 \%$ per hour.

2) - At an initial pressure of 1 bar that the weight loss rate was $2 \mathrm{~g}$, the moisture loss rate was $0.2 \%$ per hour.

3) - At an initial pressure of 0.5 bar that the weight loss rate was $1 \mathrm{~g}$, the moisture loss rate was $0.1 \%$ per hour. We note from the Tables IV and V:

4) - At an initial pressure of 1.8 bar that the weight loss was $9.5 \mathrm{~g}$ per hour.

5) - At an initial pressure of 1 bar that the weight loss rate was $3.8 \mathrm{~g}$ per hour.

6) - At an initial pressure of 0.5 bar that the weight loss rate was $2 \mathrm{~g}$ per hour.

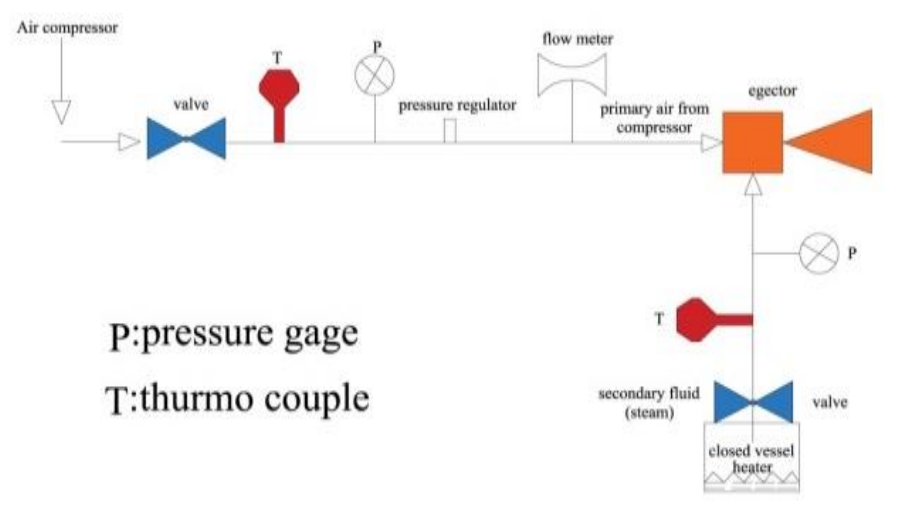

Figure 5: Schematic diagram of system 
Table 2: Temperatures in cooling and storing food [8]

\begin{tabular}{|c|c|c|}
\hline Freezing degree $\mathrm{c}^{0}$ & Degree of storage $\mathrm{c}^{0}$ & The product \\
\hline \multicolumn{3}{|c|}{ The meats } \\
\hline-2 & $0-(1.1)$ & Beef \\
\hline-2 & $0-(1.1)$ & Sheep meat \\
\hline-2.7 & 0 & Poultry meat \\
\hline-0.6 & 0.6 & Milk is pasteurized \\
\hline-2.2 & 0 & Eggs \\
\hline \multicolumn{3}{|c|}{ Vegetables } \\
\hline-0.7 & & Green beans \\
\hline \multirow[t]{2}{*}{-0.6} & 0 & Corn \\
\hline & 0 & Dried garlic \\
\hline-0.3 & 0 & Spinach \\
\hline-0.77 & 0 & Onions \\
\hline-0.61 & $3.3-10$ & Tomato \\
\hline
\end{tabular}

Table 3: The result of loss weight of one litter of water after $60 \mathrm{~min}$

\begin{tabular}{|c|c|c|c|}
\hline Time & $\begin{array}{r}\text { Loss Weight (g) at } \\
P_{P}=1.8 \\
T P=25 C^{\circ}\end{array}$ & 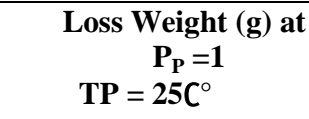 & $\begin{array}{r}\text { Loss Weight }(\mathrm{g}) \text { at } \\
\mathbf{P}_{\mathbf{P}}=0.5 \\
T P=25 C^{\circ}\end{array}$ \\
\hline 15 & 1.2 & 0.5 & 0.25 \\
\hline 30 & 2.4 & 1 & 0.5 \\
\hline 45 & 3.6 & 1.5 & 0.75 \\
\hline 60 & 4.8 & 2 & 1 \\
\hline
\end{tabular}

Table 4: Data and results for humidity loss rate at different primary pressure (Pp).

\begin{tabular}{ccc}
\hline Primary Pressure (bar) & Humidity loss Rate \% \\
\hline 1.8 & 0.5 \\
1 & 0.2 \\
0.5 & 0.1 \\
\hline
\end{tabular}

Table 5: The result of loss weight of 0.5 litter of water after $60 \mathrm{~min}$

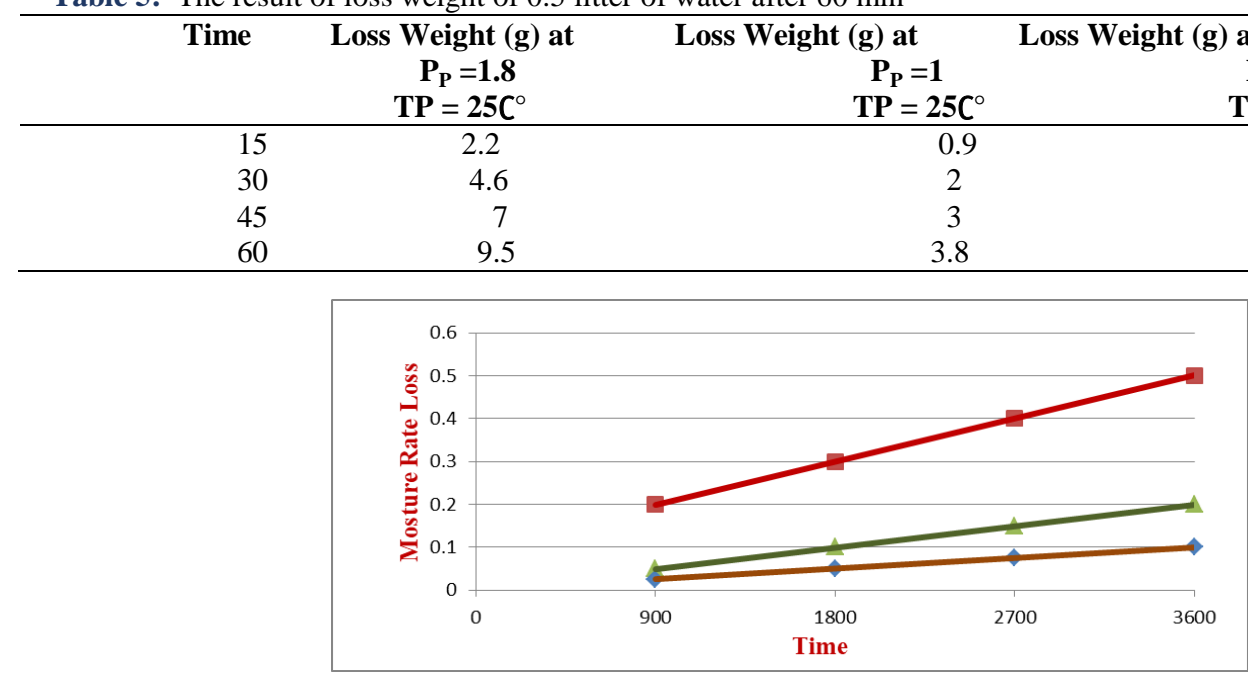

Figure 6: The relation between moisture rate loss and time due to evaporation at different primary pressure $(1.8,1$, and 0.5$)$ bar. 


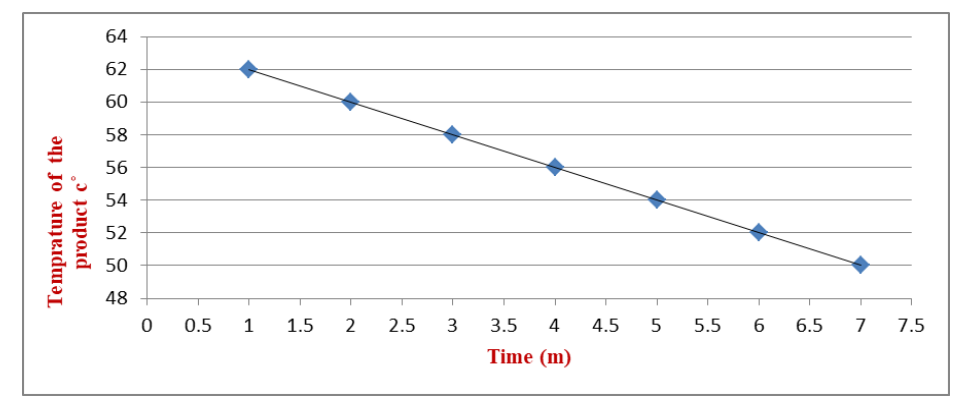

Figure 7: Relation between temperature reductions of product (litter of milk) with time at primary pressure 1.8 bar.

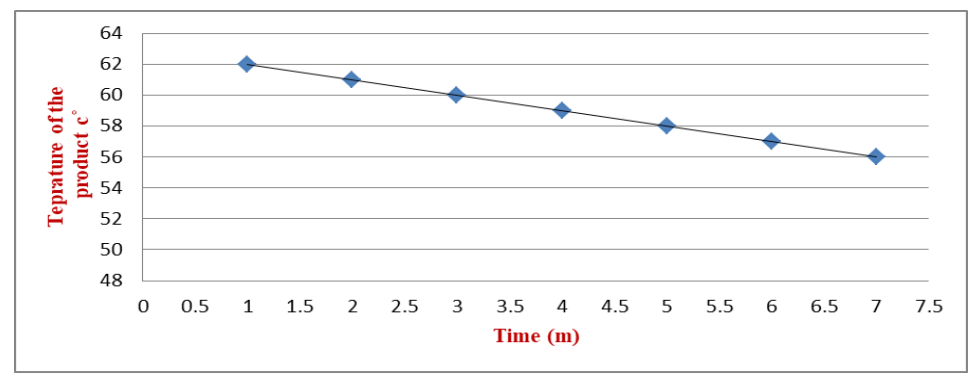

Figure 8: Relation between temperature reductions of product (litter of milk) with time at primary pressure 1 bar.

Figure 6 shows the relation between moisture rate loss and time due to evaporation at different primary pressure. At the same amount of water in the container We note at the highest initial pressure1.8 bar, there was the highest rate of moisture loss for the product and it gradually decreases as the initial pressure decreases until reach the lowest moisture loss $0.1 \%$, The shape of all these graphs is same Where the relationship is linear because the rate of evaporation is uniform at all primary pressure.

Figure 7 represents relation between temperature reductions of product (litter of milk) with time at primary pressure 1.8 bar it shows that the cooling rate of milk at $62 \mathrm{C}^{0}$ is two degree Celsius per minute.

Figure 8 represents relation between temperature reductions of product (litter of milk) with time at primary pressure 1 bar it shows that the cooling rate of milk at $62 \mathrm{C}^{0}$ is one degree Celsius per minute.

\section{Conclusions}

The practical results have shown

1) The cooling efficiency of the product increases by increasing the primary pressure.

2) The loss weight of the product increases by increasing the primary pressure.

3) The cooling efficiency of the product increases by decreasing the mass of the product.

4) Optimum temperature control is one of the most important factors to prevent food deterioration and maintain its quality

5) Finally, an extension of the present work is recommended for future experimental work, through the

using an air compressor that is larger than the user and work under higher pressures and study the efficiency of cooling in the compressor stabilization stage, designing a two-stage ejector and studying its effect on cooling processes, designing ejector with larger dimensions than the user, and using the vacuum pump instead of air compressor and compare efficiency.

\section{Nomenclatures}

$\begin{array}{lll}\text { 1. } & \mathrm{a}_{1}, \mathrm{a}_{2}, \mathrm{c}_{1}, \mathrm{c}_{2}, \mathrm{c}_{3} & \text { Coefficients } \\ \text { 2. } & \mathrm{A} & \text { Area } \mathrm{mm}^{2} \\ \text { 3. } & \mathrm{M} & \text { Mach number } \\ \text { 4. } & \mathrm{m}^{\sim} & \text { Mass flow rate } \mathrm{kg} / \mathrm{s} \\ \text { 5. } & \mathrm{N} & \text { Value of } \mathrm{cp} / \mathrm{cv} \text { adjusted for isentropic efficiency } \\ \text { 6. } & \mathrm{Pe} & \text { Vapour pressure at the suction port of the ejector (passive gas) bar } \\ \text { 7. } & \mathrm{Pg} & \text { Vapour pressure at the nozzle inlet of the ejector (active gas) bar } \\ \text { 8. } & \mathrm{PR} & \text { Pressure ratio Pg /Pe } \\ \text { 9. } & \mathrm{R} & \text { Gas constant } \\ \text { 10. } & \mathrm{T} & \text { Temperature } \mathrm{K} \\ \text { 11. } & \mathrm{V} & \text { Gas velocity } \mathrm{m} / \mathrm{s} \\ \text { 12. } & \gamma & \text { cp / cv } \\ \text { 13. } & \phi_{\mathrm{m}} & \text { Mixing coefficient } \\ \text { 14. } & \mathrm{H} & \text { Isentropic efficiency } \\ \text { 15. } & \eta_{\mathrm{P}} & \text { Isentropic efficiency }- \text { primary (active) flow through nozzle } \\ \text { 16. } & \eta_{\mathrm{m}} & \text { Isentropic efficiency }- \text { flow through diffuser } \\ \text { 17. } & \varpi & \text { Entrainment ratio }=\mathrm{ms} / \mathrm{m}\end{array}$




\section{Subscripts}

\begin{tabular}{llll}
\hline 18. & C & & Exit of ejector \\
19. & E & Inlet port of the entrained flow (passive gas) \\
20. & G & Nozzle inlet, active gas \\
21. & M & Mixed flow \\
22. & P & Primary (active) flow \\
23. & pI & Nozzle exit \\
24. & Py & Primary flow at the location of choking for the entrained flow \\
25. & S & Suction or entrained flow, passive gas \\
26. & sy & Entrained flow at the location of choking for the entrained flow \\
27. & t & Nozzle throat \\
28. & y-y & Plane of ejector cross section at the commencement of mixing section \\
29. & 1 & Nozzle exit \\
30. & 2 & Entrance of the constant-area section \\
31. & 3 & Exit of the constant-area section
\end{tabular}

\section{Author contribution}

All authors contributed equally to this work.

\section{Funding}

This research received no specific grant from any funding agency in the public, commercial, or not-for-profit sectors.

\section{Data availability statement}

The data that support the findings of this study are available on request from the corresponding author.

\section{Conflicts of interest}

The authors declare that there is no conflict of interest.

\section{References}

[1] A. Maqsood, A study of subsonic air-air ejectors with short bent mixing tubes, Ph.D. Thesis, Mechanical and Materials Eng. Dept., Univ. of Queen's, Canada, 2008.

[2] A. Al-Nuaimi1, M. Worall, S. Riffat, Preliminary Study of effects of primary and back pressure on performance of supersonic ejector driven by compressed air, $17^{\text {th }}$ International Conference on Sustainable Energy Technologies, Wuhan, China, $21^{\text {st }}-23^{\text {rd }}$ of August 2018.

[3] P. Watanawanyooa, S. Chaitepb, Performance evaluation of a water ejection type in vacuum drying system, J. Energy Procedia., 52 (2014) 588-597. https://doi.org/10.1016/j.egypro.2014.07.114

[4] J.J. Schwegman, R. Stefan, Basic cycle development techniques for lyophilized products, https://www.scribd.com/document/252192875/Basic-Cycle-Development-Techniques-for-Lyophilized-Products, 2009.

[5] M. A. Saad, "Compressible fluid flow," 2nd Edition, Englewood Cliffs, 1985.

[6] B.J. Huang, J.M. Chang, C.P. Wang, V.A. Petrenko, A 1-D analysis of ejector performance, International journal of refrigeration, Int J Refrig., 22 (1999) 354-364. https://doi.org/10.1016/S0140-7007(99)00004-3

[7] J.M.A. Dandachi, Steam air ejector performance and its dimensional parameters, Ph.D. Thesis, Chemical Eng. Dept., Univ. of Loughborough, London, 1990.

[8] D. M., Parikh, Vacuum drying: basics and application, J. Chem. Eng., 122 (2015) 48-54.

[9] P. V. Eeden, D. Ercolani, A Method for prediction of Gas/Gas ejector performance, Impiantistica Italiana, p. 76, 2013.

[10] Q. J. Abdul Ghafoor, Design and manufacture of an ejector as part of a cooling system, Master thesis, Mechanical Eng. Dept. Univ. of Technology, 1992. 